\title{
A study of molecular mechanisms for spreading of kanamycin resistance gene among ruminal bacteria
}

\author{
P Pristas, I Vanat, N Kostrabova, P Javorsky \\ Institute of Animal Physiology, Slovak Academy of Sciences, Soltésovej 4-6, 04001 Kosice, Slovakia
}

The rumen is one of the most complex microbial ecosystems in the world, and forms on environment especially suited for the study of gene movement and exchange in natural conditions. Antibiotic resistance genes present a good model for studies. In our previous work (Pristas et al, in press) we have detected a Tn 5 like aphll gene among kanamycinresistant ruminal streptococci and selenomonas. From both microorganisms resistance genes were cloned and shown to confer resistance to kanamycin sensitive Escherichia coli. The abundance of aphll like sequences in populations of bacteria was analyzed by DNA-DNA hybridization.

It was found that different strategies are used by Gram-negative resp. Gram-positive bacteria:

-from Gram-negative Selenomonas rumi- nantium kanamycin-resistance was transferred to $E$. coli using free DNA transformation. Probably plasmids and classical type II transposons are involved in the spreading of aphll resistance gene;

-a different situation occurred for the Grampositive streptococci. No plasmid DNA was detected in a strain of Streptococcus bovis. However, it was shown that a cloned streptococcal kanamycin resistance determinant could be transferred between $E$. coli cells by conjugation. Upon conjugation, site specific integration of the aphll determinant into host genome was observed, resembling those found for some integrons (Collins et al, 1993, Mol Microbiol, 9, 41-52).

Detailed analysis both of elements involved in the spreading of kanamycin resistance among ruminal bacteria is under progress. 